\title{
Qualidade de pêssegos em pomares conduzidos de forma convencional e integrada
}

\author{
Peach quality of conventional and integrated production orchards
}

\author{
Renato Trevisan $^{1}$ Emerson Dias Gonçalves ${ }^{1}$ Enilton Fick Coutinho $^{2}$
}

\section{RESUMO}

\begin{abstract}
O objetivo do trabalho foi avaliar as características de qualidade de frutas nos sistemas de produção integrada (PIF) e produção convencional (PC) em pomar de pessegueiro, cultivar Eldorado, no município de Candiota, RS. Os sistemas de produção foram caracterizados da seguinte forma: PC, PIF e PIF-ráfia. No PC, prevaleceu o manejo e práticas convencionais utilizadas pelo produtor. No PIF, foram utilizadas as práticas de manejo definidas nas Normas para Produção Integrada de Pêssego, já no PIF-ráfia, o diferencial foi à implantação de uma manta plástica de ráfia sob a copa das plantas. $O$ delineamento experimental adotado foi o de blocos casualizados, com quatro repetições e as médias foram submetidas ao teste de Duncan a $5 \%$ de significância. As variáveis avaliadas foram: coloração da epiderme, sólidos solúveis totais (SST), acidez total titulável (ATT), relação SST/ATT e firmeza de polpa. Os resultados mostraram que a utilização de plástico de ráfia sob a copa das plantas na cultivar Eldorado, intensificou a coloração vermelha na epiderme e não interferiu nas qualidades químicas das frutas.
\end{abstract}

Palavras-chave: Prunus pesica, CIEL*a*b*, qualidade de fruto.

\section{ABSTRACT}

The aim of this work was to evaluate the fruits quality characteristics in the systems of Fruit integrated production (FIP) and conventional production $(C P)$ in peach tree orchard of Eldorado peach, in the town of Candiota, RS. The production systems were characterized in the following way: CP, FIP and FIP-raffia. In CP, the handling and conventional practices used by the producer prevailed. In FIP the handling practices were of agreement the Norms for Integrated Production Peach, yet in FIP-raffia, the deferential was to the implantation of a raffia plastic blanket under tree canopy. The experimental design was in casualized blocks, with four replicates and the averages were submitted to 5\% Duncan test. The appraised variables were: epidermis coloration, total soluble solids (TSS), total tritratable acidity (TTA), relationship with TSS/TTA and pulp firmness. The results showed that the use of raffia plastic under the tree canopy, intensified the red coloration in the epidermis of Eldorado peach, and didn't interfere in the fruits chemical qualities.

Key words: Prunus pesica, CIEL*a*b *, fruit quality.

\section{INTRODUÇÃO}

O Brasil é o terceiro maior produtor mundial de frutas frescas, atrás da China e da Índia, com cerca de 38 milhões de toneladas/ano. As frutas frescas renderam ao Brasil US\$ 335,3 milhões em 2003, com aumento de 39,1\% em comparação com 2002. Apesar disso, as exportações brasileiras correspondem a $1,6 \%$ em divisas e $2 \%$ em volume sobre as exportações mundiais do setor (JORNAL DA FRUTA, 2004).

Para impulsionar as exportações em fruticultura, o Brasil vem intensificando as ações no que se refere à qualidade de frutas. De acordo com as exigências do mercado europeu, a implantação do Sistema Integrado de Frutas (PIF) passou a ser uma das principais diretrizes da estratégia para elevar as exportações de frutas no Brasil. A produção integrada é um sistema de exploração agrária que produz frutas de qualidade e sanidade, seguindo normas de sustentabilidade ambiental, e segurança alimentar e de viabilidade econômica, mediante o uso de tecnologias não agressivas ao meio ambiente e ao homem (MATTOS et al., 2002). Esse novo sistema de produção é uma alternativa para a produção de frutas de qualidade, pois utiliza práticas de manejo do solo e da planta conjuntamente, procurando equacionar os problemas através de uma visão multidisciplinar e

\footnotetext{
${ }^{1}$ Engenheiro Agrônomo, Bolsista Recém-Doutor Conselho Nacional de Desenvolvimento Científico e Tecnológico (CNPq), Embrapa Clima Temperado. E-mail: trevisan@cpact.embrapa.br

${ }^{2 i}$ Engenheiro Agrônomo. Doutor Embrapa Clima Temperado, CP 403, 96001-970, Pelotas RS. E-mail: enilton@cpact.embrapa.br.
} 
não a aplicação de práticas isoladas como ocorre na fruticultura convencional (FACHINELLO et al., 2002), embora as frutas produzidas no sistema integrado possam apresentar aparência externa de menor valor comercial.

Trabalhos dentro desta nova concepção de cultivo reportam resultados relevantes quanto à implementação do sistema, demonstrando que é possível conduzir pomares de pessegueiro com cultivo mínimo do solo, reduzir o uso de agroquímicos de síntese e melhorar a qualidade de frutas sem aumentar os gastos e riscos à sociedade.

Neste contexto, o consumidor vem mudando seus hábitos alimentares, incorporando as frutas nas suas refeições diárias, estabelecendo novos critérios de qualidade, os quais, ele mesmo pode julgar através dos sentidos que são a visão (cor da epiderme e tamanho), tato (firmeza) e olfato (odor).

Vários autores relatam que a coloração da epiderme das frutas é o principal parâmetro de qualidade atribuído pelo consumidor, principalmente no que se refere à coloração vermelha (LUCHINGER, 2000; LI et al., 2002; TREVISAN, 2003).

As plantas, quando sujeitas a determinadas intervenções, como podas de verão e inverno, nutrição (FALLAHI \& MOHAN, 2000), reguladores de crescimento (MILLER, 1988), maior disponibilidade de radiação solar, com uso de materiais refletivos, (LAYNE et al., 2002) afetam não só o crescimento como a diferenciação floral, o vingamento e a coloração das frutas (BIBLE \& SINGHA, 1993).

Vários estudos têm mostrado que, a disponibilidade de luz adicional para as plantas, como o uso de material refletivo no solo, entre fileiras ou abaixo da copa, intensifica a coloração vermelha na epiderme de pêssegos e maçãs (LAYNE et al., 2001; TREVISAN, 2003).

O trabalho teve como objetivo avaliar as qualidades físicas e químicas das frutas de pessegueiro no sistema de produção integrada, utilizando plástico de ráfia na cobertura, comparado ao sistema convencional.

\section{MATERIAL E MÉTODOS}

Na safra de 2001/02, foram obtidos frutos de pêssego da cultivar Eldorado (dupla-finalidade) provenientes de um pomar comercial de pessegueiro com oito anos de idade, que se encontra no Sistema de Produção Integrada (PIF), há três anos. As plantas foram conduzidas na forma de taça e espaçadas com $6 \times 2 \mathrm{~m}$. O pomar está localizado no município de
Candiota, região sul do Rio Grande do Sul, a qual vem se destacando na fruticultura.

Para o trabalho, utilizaram-se frutos provenientes de dois pomares; um do sistema de produção convencional (PC) e outro do PIF. Estes se encontram isolados por uma barreira dupla de plantas (ciprestes). No sistema PC, foram adotados o manejo e as práticas culturais normalmente utilizados pelo produtor, tratamentos fitossanitários fixo, manejo do solo com grades na linha de plantas, sem utilização de poda verde e sem o monitoramento de pragas e doenças. No sistema PIF, foram adotadas as técnicas de manejo definidas nas normas técnicas (FACHINELLO et al., 2003). No sistema PIF, sob a projeção da copa das plantas, quatro semanas antes da colheita foram fixados na superfície do solo, através de trincheiras, plástico de ráfia de coloração branca, obtida de sacos de adubo abertos. Estes foram costurados um a um de forma a cobrir as plantas da unidade experimental, com aproximadamente $1 \mathrm{~m}$ de largura por $8 \mathrm{~m}$ de comprimento. As frutas provenientes deste sistema foram comparadas com frutas provenientes do sistema PIF, sem as coberturas plásticas e também comparadas com as frutas do PC. Foram constituídos, assim, os sistemas (tratamentos): PIF-ráfia; PIF e PC.

Variáveis analisadas: Coloração das frutas: mensurada com colorímetro eletrônico, marca Minolta 300, com iluminante D65, e abertura de $8 \mathrm{~mm}$, no sistema registrado pela Commission Internationale de I'Eclairage (CIE) $\mathrm{L}^{*}, \mathrm{a}^{*}$ e b* usando nas coordenadas espaciais da cor. O colorímetro, antes do início das leituras, foi calibrado sob uma cerâmica branca stander. Neste sistema de representação de cor, os valores $\mathrm{L} * \mathrm{a} * \mathrm{e} \mathrm{b} *$ descrevem a uniformidade da cor no espaço tridimensional, onde o valor $\mathrm{L} *$ corresponde a escuro-brilhoso (0, preto; 100 branco) e representa a leveza relativa da cor. Os valores de $\left(\mathrm{a}^{*}\right)$ correspondem à escala do verde ao vermelho ( $a^{*}$ negativo, verde; a* positivo, vermelho) e os valores de $\left(b^{*}\right)$ correspondem à escala do azul ao amarelo ( $b^{*}$ negativos, azul; $b^{*}$ positivo, amarelo). A partir destes valores, calcularam-se os valores da tonalidade da cor (ângulo $h^{\circ}$ ), expressa em graus, pela fórmula $h^{\circ}=$ $\tan ^{-1} \mathrm{~b}^{*} / \mathrm{a}^{*}$. O ângulo $\mathrm{h}^{\circ}$ é a variável que melhor representa a evolução da cor na epiderme. Foram realizadas quatro leituras na região equatorial de cada fruta avaliada; firmeza de polpa: determinada com penetrômetro manual, (Effe-Gi FT-011) com ponteira de $8 \mathrm{~mm}$ de diâmetro, em dois lados da 
região equatorial da fruta, da qual, previamente, foi retirada a epiderme, os resultados foram expressos em libras; Sólidos solúveis totais (SST): determinado com refratômetro manual, sobre o qual foi colocada uma gota de suco das frutas, expresso graus Brix; Acidez Titulável (ATT): determinada por titulação de $10 \mathrm{ml}$ de suco, diluídos em 100ml de água destilada, com uma solução de $\mathrm{NaOH} 0,1 \mathrm{~N}$ até pH 8,1 e os resultados expressos em percentagem de ácido cítrico, e relação SST/ATT. A colheita foi realizada na primeira quinzena de dezembro (2001), em duas épocas (5/12 e 12/12).

O delineamento experimental utilizado no campo foi blocos casualizados, com quatro repetições e três plantas por parcela. Em laboratório, as avaliações foram realizadas em 15 frutas por repetição. Os dados foram submetidos à análise de variância pelo programa Sanest, e quando da significância, realizou-se o Teste de Duncan em nível de 5\% de probabilidade de erro.

\section{RESULTADOS E DISCUSSÃO}

Pelos resultados, verificou-se que o brilho, ou luminosidade da cor, não diferiu entre os sistemas estudados. Entretanto, ao se analisar os valores de $a^{*}$ (cor de superfície) verificou-se que, quando da utilização da ráfia em cobertura no solo, esta atribuiu maiores valores em relação aos PIF e PC, diferindo estatisticamente. Já com a cor de fundo $\left(b^{*}\right)$, o sistema PC diferiu significativamente do PIF-ráfia e PIF, com valor de $b^{*}$ maior, proporcionando assim frutas mais amarelas. Quanto ao ângulo $\mathrm{h}^{\mathrm{o}}$, tonalidade da cor, no sistema PIFráfia, este obteve um menor ângulo, diferindo dos demais sistemas, proporcionando uma maior intensidade da cor vermelha nas frutas (Tabela 1).

Estes resultados obtidos corroboram com os de LAYNE et al. (2001 e 2002) que observaram aumentos percentuais de até $46 \%$ da coloração vermelha em pêssegos, justificando assim o uso deste material e a exigência de consumidores europeus e brasileiros, no aumento da intensidade da cor vermelha na epiderme das frutas.

Ao utilizar plásticos refletivos sob copa das plantas, como o de ráfia, na cultivar Maciel, TREVISAN (2003) constatou aumento dos valores de $\mathrm{a}^{*}$ (vermelho) e conseqüentemente o ângulo $\mathrm{h}^{\mathrm{o}}$, corroborando os resultados deste trabalho. Segundo JU et al., (1999), este incremento da coloração vermelha na epiderme é conseqüência da ação dos plásticos ao refletirem a luz. Eles estimulam a síntese das antocianinas, as quais aceleram a expressão do gene para a enzima flavonóide-3-oglicosil transferase, enzima esta responsável pela pigmentação vermelha. Outra enzima envolvida neste processo em conseqüência do uso destes materiais, segundo WILSON (1994), é a fenil amônia liase (PAL). Estas enzimas, bem como as antocianinas, não foram determinadas neste trabalho.

Quanto à cor de fundo $\left(b^{*}\right)$, observa-se que no sistema PC, as frutas apresentaram epiderme mais amarela. Isto pode ser devido ao fato de que, nas plantas nos sistemas PIF-ráfia e PIF, foi realizado poda verde na pré-colheita. Esta poda permitiu assim uma melhor e maior radiação solar nas plantas e frutas, estimulando a síntese das antocianinas, proporcionando aumento da coloração vermelha, ao passo que, no sistema PC, esta poda não foi executada, não permitindo assim maior luminosidade nas frutas. Entretanto, TREVISAN (2003) não observou estes resultados na cultivar Maciel, embora tenha realizado poda verde na pré-colheita nas plantas que estavam sob o material de ráfia. As épocas de colheita não interferiram nos parâmetros de coloração das frutas $\left(\mathrm{CEL}^{*} \mathrm{a}^{*} \mathrm{~b}^{*}\right)$, contrariando resultados de outros trabalhos que relatam que as frutas, ao permanecerem por mais tempo na planta, expostas à radiação solar, ou adicional (plásticos) aumentam a coloração de superfície $\left(a^{*}\right)$ e a tonalidade da cor (ângulo $h^{\circ}$ ).

Com relação às características de sabor (SST, ATT e reação SST/ATT) não houve diferença

Tabela 1 - Média das observações nos parâmetros de coloração nos sistemas de produção em frutas de pêssego cultivar Eldorado, Embrapa Clima Temperado, Pelotas, RS, 2004.

Coordenadas CIEL*a*b*

\begin{tabular}{lcccc} 
Sistemas & $\mathrm{L}^{*}$ & $\mathrm{a}^{*}$ & $\mathrm{~b}^{*}$ & $\mathrm{~h}^{\mathbf{0}}$ \\
\hline PIF- Ráfia & $65,05^{\text {ns }}$ & $8,04 \mathrm{a}$ & $45,28 \mathrm{~b}$ & $79,90 \mathrm{~b}$ \\
PIF & 64,53 & $5,68 \mathrm{~b}$ & $45,74 \mathrm{~b}$ & $83,26 \mathrm{a}$ \\
PC & 64,28 & $5,42 \mathrm{~b}$ & $48,66 \mathrm{a}$ & $83,51 \mathrm{a}$ \\
\hline Média geral & 64,62 & 6,38 & 46,56 & 82,22 \\
CV $(\%):$ & 1,64 & 5,78 & 2,73 & 2,49 \\
\hline
\end{tabular}

$\mathrm{L}^{*}=$ Luminosidade $(0=$ preto $; 100=$ branco $) ; \mathrm{a}^{*}=$ vermelho $(+\mathrm{a}$ $=$ vermelho; - a verde $) ; b^{*}=$ amarelo $(+b=$ amarelo; $-\mathrm{b}=\mathrm{azul})$; ângulo $\mathrm{h}^{\circ}\left(0^{\circ}=\right.$ vermelho; $90^{\circ}=$ amarelo; $180^{\circ}=$ verde; $360^{\circ}=$ azul). ns = não significativo.

Médias não seguidas pela mesma letra na coluna diferem entre si pelo teste de Duncan em nível de 5\% de probabilidade de erro. 
significativa nos sistemas estudados, entretanto as frutas, no sistema PC, apresentaram-se menos firmes, diferindo dos tratamentos PIF e PIF-ráfia (Tabela 2).

Estes resultados, quanto à firmeza de polpa, concordam com os obtidos por FACHINELLO et al., (2003) os quais relatam que as frutas provenientes do PIF apresentaram maior resistência na polpa, entretanto, deve-se ressaltar que os autores trabalharam com a cultivar Diamante, predominantemente destinada à indústria, que tem como característica polpa mais firme do que a cultivar Eldorado, que é de dupla-finalidade.

Pela Tabela 3, verificou-se que, entre as colheitas, não houve diferenças significativas em relação à firmeza de polpa, SST e relação SST/ATT, contrariando ALTUBE et al. (1999) os quais observaram maior conteúdo de sólidos totais nas frutas de pêssego que permaneceram por mais tempo na planta. Porém, na segunda colheita, as frutas apresentaram maior acidez. Possivelmente o fator tempo de permanência na planta tenha interferido na degradação dos açúcares, convertendo-os em ácidos (KAYS, 1991).

Tabela 2 - Média das observações nas características físicas e químicas, em frutas de pêssego cultivar Eldorado, nos sistemas de produção avaliados. Embrapa Clima Temperado, Pelotas, RS, 2004.

\begin{tabular}{lllll}
\hline Sistemas & Firmeza (lb) & $\begin{array}{l}\text { SST } \\
{ }^{\circ} \text { Brix }\end{array}$ & $\begin{array}{l}\text { ATT (\% } \\
\text { ác. cítrico) }\end{array}$ & $\begin{array}{l}\text { Relação } \\
\text { SST/ATT }\end{array}$ \\
\hline PIF- Ráfia & $7,49 \mathrm{a}$ & $13,05^{\mathrm{ns}}$ & $0,64^{\mathrm{ns}}$ & $20,70^{\mathrm{ns}}$ \\
PIF & $7,48 \mathrm{a}$ & 12,54 & 0,68 & 18,22 \\
PC & $6,10 \mathrm{~b}$ & 12,67 & 0,67 & 18,94 \\
\hline Média geral & 7,02 & 12,75 & 0,67 & 19,29 \\
CV $(\%):$ & 16,02 & 6,62 & 7,82 & 11,65 \\
\hline
\end{tabular}

Médias não seguidas pela mesma letra na coluna diferem entre si pelo teste de Duncan em nível de 5\% de probabilidade de erro. ns = não significativo

Tabela 3 - Média das observações nas características físicas e químicas, em frutas de pêssego cultivar Eldorado, nas épocas de colheita. Embrapa Clima Temperado, Pelotas, RS, 2004.

\begin{tabular}{lcccc}
\hline Colheitas & Firmeza (lb) & $\begin{array}{c}\text { SST } \\
{ }^{\circ} \text { Brix }\end{array}$ & $\begin{array}{c}\text { ATT } \\
(\% \text { ác. Málico })\end{array}$ & $\begin{array}{c}\text { Relação } \\
\text { SST/ATT }\end{array}$ \\
\hline $5 / 12$ & $7,48 \mathrm{~ns}$ & $12,90 \mathrm{~ns}$ & $0,63 \mathrm{~b}$ & $20,33 \mathrm{~ns}$ \\
$12 / 12$ & 6,6 & 12,61 & $0,70 \mathrm{a}$ & 18,24 \\
\hline
\end{tabular}

Médias não seguidas pela mesma letra na coluna diferem entre si pelo teste de Duncan em nível de 5\% de probabilidade de erro. ns = não significativo

\section{CONCLUSÃO}

O sistema de produção integrada de frutas, com o uso da ráfia sob a copa das plantas, possibilita maior intensidade da coloração vermelha na epiderme; o sistema PIF e PIF-ráfia, proporciona maior firmeza de polpa;

os sistemas PIF e PIF-ráfia, não melhoram as qualidades químicas e,

a acidez aumenta com a permanência das frutas na planta.

\section{REFERÊNCIAS BIBLIOGRÁFICAS}

ALTUBE, H.A. et al. Determinacion de los índices de cosecha para duraznos (Prunus persica) (L) Batsch) Springcrest. Revista Brasileira de Fruticultura, Jaboticabal, v.21,n.2,p.166-170, 1999.

BIBLE, B.B.; SINGHA, S. Canopy position influences CIELAB coordinates of peach color. HortScience, Alexandria, v.28, p.992-993, 1993.

FALLAHI, E.; MOHAN, S.K. Influence of nitrogen and rootstock on tree growth, precocity, fruit quality, leaf mineral nutrients, and fire blight in Scarlet Gala apple. HortTechnology, Alexandria, v.10, n.3, p.589-596, 2000.

FACHINELLO, J.C. et al. Normas Técnicas e Documentos de Acompanhamento da Produção Integrada de Pêssego. Pelotas:Universidade Federal de Pelotas. Faculdade de Agronomia Eliseu Maciel, 2003. 91p. (Documentos 01).

FACHINELLO, J.C et al. Produção Integrada de Pêssegos na Região de Pelotas-RS. In: SEMINÁRIO BRASILEIRO DE PRODUÇÃO INTEGRADA DE FRUTAS, 4., 2002, Bento Gonçalves, RS. Anais... Bento Gonçalves : Embrapa Uva e Vinho, 2002. p.71.

FACHINELLO, J.C et al. Produção integrada de pêssegos: três anos de experiência na região de Pelotas, RS. Revista Brasileira de Fruticultura, Jaboticabal, v,25, n.2, p.256-258, 2003.

JORNAL DA FRUITA. Exportações de frutas frescas brasileiras alcançam UU\$ 335,3 milhões. Friburgo, SC. 2004. p.12.

JU, Z. et al. Coloration potential, anthocyanin accumulation and enzyme activity in fruit of commercial apple cultivars and their F1 progeny. Scientia Horticulturae, Amsterdam, v.79, p.3950, 1999.

KAYS, S.J. Development of plants and plant parts. In: KAYS, S.J. Postharvest physiology of perishable plant products. New York : Van Nostrand Reinhold, 1991. p.257-333.

LAYNE, D.R.; JIANG, Z.; RUSHING, J.W. Tree fruit reflective film improves red skin coloration and advances maturity in peach. HortTechnology, Alexandria, v.11, n.2, p.234-242, 2001.

LAYNE, D.R.; JIANG, Z.; RUSHING, J.W. The influence of reflective film and retain on red skin coloration and maturity of gala apples. HortTechnology, Alexandria, v.12, n.4, p.640-644, 2002. 
LI, Z.H.; GEMMA. H.; IWAHORI. Stimulation of Fuji apple skin color by ethephon and phosphorus-calcium mixed compounds in relation to flavonoid synthesis. Scientia Horticulturae, Amsterdam, v.94, p.193-199, 2002.

LUCHISINGER, L. Tecnologia e manejo pós-colheita e seu impacto na qualidade de frutas ao consumidor, índices de colheita e manejo pós-colheita em frutas de caroço. In: MERCOFRUT, 2., 2000, Pelotas. Anais... Pelotas, RS : Embrapa Clima Temperado, 2000. p.193-200.

MATTOS, M.L.T.; FACHINELLO, J.C. Resíduos de pesticidas em pêssegos de Produção Integrada. In: SEMINÁRIO BRASILEIRO DE PRODUÇÃO INTEGRADA DE FRUTAS, 4.,
2002, Bento Gonçalves, RS. Anais... Bento Gonçalves : Embrapa Uva e Vinho, 2002. p.73.

MILLER, S.S. Plant bioregulators in apple and pear culture. HortScience Revision. Alexandria, v.10, p.309-401, 1988.

TREVISAN, R. Avaliação da qualidade de pêssegos Cv. Maciel, em função do manejo fitotécnico. 2003. 122p. Tese (Doutorado em Ciências - Fruticultura de Clima Temperado) Fruticultura de Clima Temperado, FAEM, UFPel.

WILSON, R. Potential of induced resistance to control post harvest diseases of fruits and vegetables. Plant disease, Saint Paul, v.18, n.9, p.837-844, 1994 